Katja Novitskova

\title{
Patterns of Activation
}

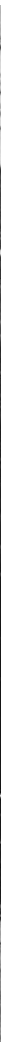



or an obscured pattern. Apophenia is a psychological tendency to see patterns and meaning where there might be none: in stock exchange, in religiously charged objects or images taken on Mars.

In Pattern of Activation (on Mars), I set up a scene in a basement of the gallery space that consisted of a backdrop print with an image of the Martian surface taken by a robotic rover, a large sculpture of a red arrow, some stones and a photographic cutout sculpture of a marabou bird. I placed a cheap camera in front of the installation and streamed the live feed from it onto a TV screen in the gallery space. The work was initially inspired by the conspiracy theory that Stanley Kubrick filmed the Moon landing in a film studio somewhere in Hollywood.

The rover missions to Mars of the last decade or so (called Spirit, Opportunity and Curiosity) have captured and sent millions of high resolution images to Earth. Since no human being has ever been on the planet, these constructed photographs taken by robots are the only way for us to 'see' what it is like on the surface. This has become an ultimate domain for both professional and amateur apophenia: scientists are misrecognising patterns of possible signs of life or water, while conspiracy theorists are misidentifying boulders as pieces of broken buildings of ancient Martian civilisations. Mixing both of these outlooks I approximated the form of a future robotic rover to look like an ancient bird. And the arrows that are often used in the analysis of photographs from Mars become actual features of the landscape. As seen on the TV screen, all the elements of the installation blend together into a low-resolution but convincingly real footage.
The ability to 'see' patterns has now also been introduced to complex algorithms and so-called AIs of different kinds. And now once again, the questions of attention arise in interesting ways. When works of art become data patterns for an AI to 'learn' or identify, what kind of elements would it be paying its own attention to, and how; what elements would it be learning through and what forms would its apophenia take? Since I've found out about deep learning algorithms I've begun to make art works that are intentionally targeting not only human eyes but also those new potential ones of world-seeing algorithms. I began using images of animals that are not viral in any way but come from certain important data sets, graphs of temperature changes in the age of climate change and other obscure patterns. Would they see these assemblages differently compared to something like a 20th century minimalist sculpture? Would they be able to recognise a change in this art-making approach from the one that was only meant for a specifically human perception? The logic of symbolic and visual pattern making may have to be shifting constantly in response to these other forms of consciousness. Even if the artificial intelligence technologies will never advance to a 'general AI' understanding, these questions offer a way to expand the understanding of art outside of narrow categories of sociopolitical history, culture and geography (a person who has never encountered installation art in a museum might also be unable to recognise the signal from noise in art assemblages). These are not sciencefictional questions but rather rhetorical ones, aimed at analysing what art is and could be tomorrow. 

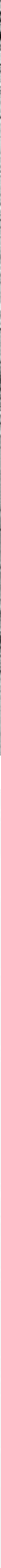
Architecture and Naturing Affairs

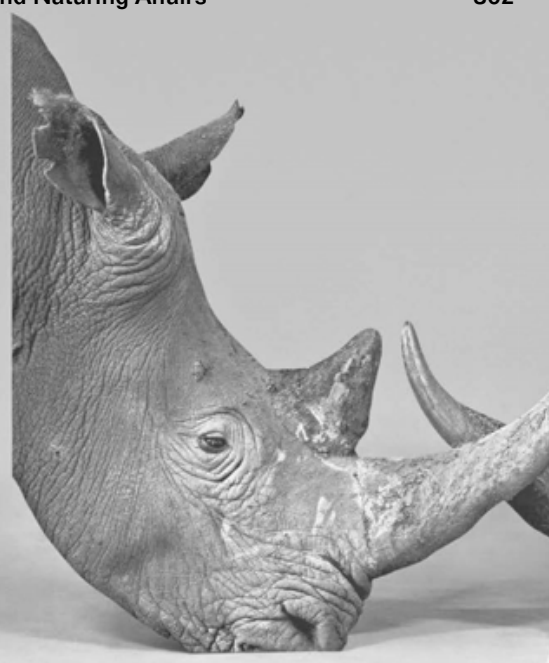

302

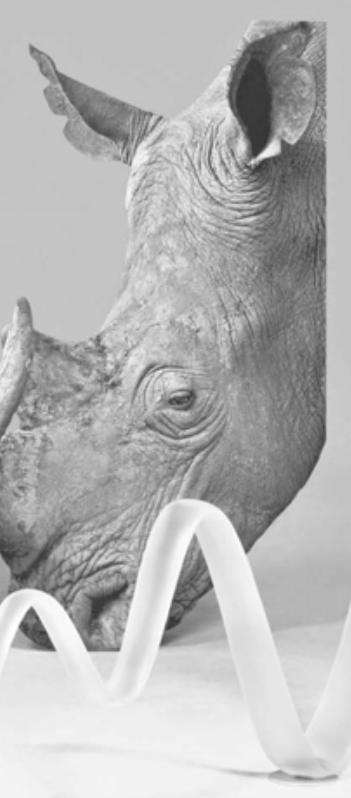

III Inhabiting

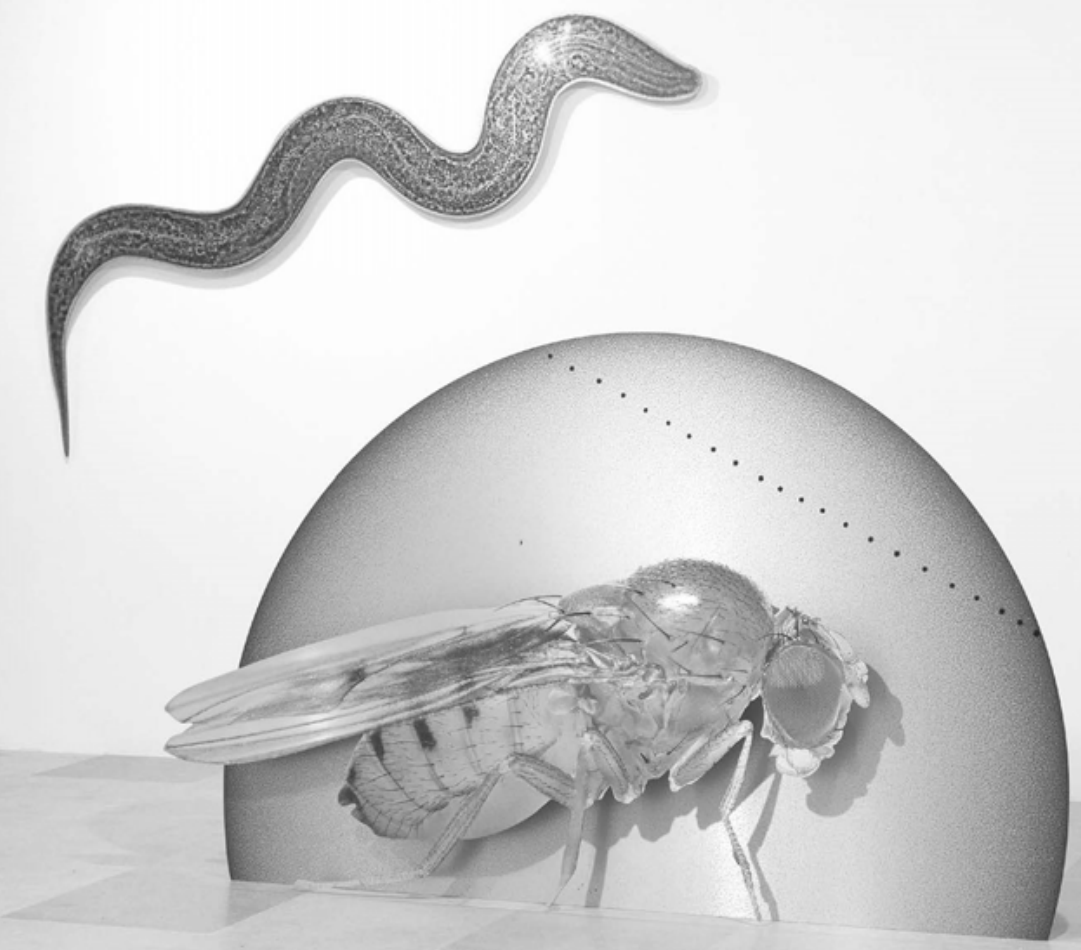




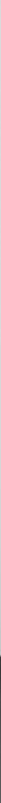

References and influences

Assamblage Theory by Manuel DeLanda https://edinburghuniversitypress.com/ book-assemblage-theory.html

A Sea of Data: Apophenia and Pattern (Mis-)Recognition by Hito Steyerl

https://www.e-flux.com/journal/72/60480/

a-sea-of-data-apophenia-and-pattern-mis-recognition/

Animal Aesthetics by Wolfgang Welsch

http://hdl.handle.net/2027/spo.7523862.0002.015

Towards a Poetics of Artificial Superintelligence by Nora N. Khan

https://medium.com/after-us/towards-a-poetics-ofartificial-superintelligence-ebff11d2d249

The Post-Anthropocene by Benjamin Bratton https://www.youtube.com/watch?v=FrNEHCZm_Sc

Seeing Like a Rover: How Robots, Teams, and Images Craft Knowledge of Mars by Janet Vertesi

https://www.press.uchicago.edu/ucp/books/book/ chicago/S/bo18295743.html 